\title{
Advancing the integration of hospital IT
}

\section{Pitfalls and perspectives when replacing specialized software for high-risk environments with enterprise system extensions}

Carsten Engelmann1; Dzifa Ametowobla²

'Department of Pediatric Surgery, Klinikum Brandenburg, Medical University Brandenburg Germany;

${ }^{2}$ Technical University Berlin, Institute for Sociology, Berlin, Germany

\section{Keywords}

Process steering software, surgery, operation room list, enterprise systems, user interface

\section{Summary}

Background: Planning and controlling surgical operations hugely impacts upon productivity, patient safety, and surgeons' careers. Established, specialized software for this task is being increasingly replaced by "Operating Room (OR)-modules" appended to enterprise-wide resource planning (ERP) systems. As a result, usability problems are re-emerging and require developers' attention. Objective: Systematic evaluation of the functionality and social repercussions of a global, marketleading IT business control system (SAP R3, Germany), adapted for real-time OR process steering. Methods: Field study involving document analyses, interviews, and a 73-item survey addressed to 77 qualified (> 1-year system experience) senior planning executives (end users; "planners") working in surgical departments of university hospitals.

Results: Planners reported that $57 \%$ of electronic operation requests contained contradictory information. Key screens contained clinically irrelevant areas $(36+/-29 \%)$. Compared to the legacy system, users reported either no improvements or worse performance, in regard to co-ordination of OR stakeholders, intra-day program changes, and safety. Planners concluded that the ERP-planning module was "non-intuitive" $(66 \%)$, increased planning work $(56 \%, p=0.002)$, and did not impact upon either organizational mishap spectrum or frequency. Interviews evidenced intra-institutional power shifts due to increased system complexity. Planners resented e.g. a trend towards increased personal culpability for mishap. Conclusions: Highly complex enterprise system extensions may not be directly suited to specific process steering tasks in a high risk/low error-environment like the OR.

In view of surgeons' high primary task load, the repeated call for simpler IT is an imperative for ERP extensions. System design should consider a) that current OR IT suffers from an input limitation regarding planning-relevant real-time data, and $b$ ) that there are social processes that strongly affect planning and particularly ERP use beyond algorithms.

Real improvement of clinical IT tools requires their independent evaluation according to standards developed for pharmaceutical subjects.

\section{Correspondence to}

Carsten Engelmann, MD, PhD

Department of Pediatric Surgery

Klinikum Brandenburg

Medical University Brandenburg Theodor Fontane

Hochstr. 29

14770 Brandenburg

Germany

Email: ceng@mailbox.org

phone: 00493381411271

fax: 00493381411809

mobile: 00491722620912
Appl Clin Inform 2017; 8: 515-528

https://doi.org/10.4338/ACl-2016-06-RA-0100

received: June 27, 2016

accepted: March 5, 2017

published: May 17, 2017

Citation: Engelmann C, Ametowobla D. Advancing the integration of hospital IT: pitfalls and perspectives when replacing specialized software for high-risk environments with enterprise system extensions. Appl Clin Inform 2017; 8: 515-528

https://doi.org/10.4338/ACl-2016-06-RA-0100 


\section{Background and Significance}

This article deals with the impact of "enterprise systems" on process steering in health care environments, including the design of operation programs in surgical disciplines:

The "OR List" is a continuously updated schedule (synonym: plan) of the day's operations. Viewed abstractly, it summarizes a surgical department's activities and contains patient names, diagnoses, planned operations and the important staffing information. For individual surgeons, the "List" has high career relevance in that it is the site of negotiations for interesting operations. For the hospital administration it provides a record of the OR, which is a major source of revenue. To accommodate this, institutions increasingly replace legacy planning software (basically simple word processed tables interlinked with laboratory and radiology software) with "planning modules" from fully integrated Enterprise Resource Planning Systems (ERP or enterprise systems; synonym: Business Process Control Systems, BPCS), which are usually already in place for billing, accounting and stock control. These steer [1] in real-time [2] (i.e. permanently and with instant results) current $a c$ tivities in the OR suite and associated areas. However, enterprise systems originally featured complex interfaces that required a considerable level of user expertise. Such specialized expertise was traditionally delivered by business specialists, working in focused and quiet environments. In contrast, due to competing clinical tasks, surgical operation planners do not usually have these resources at their disposal.

A search of the literature (February 2017) reveals that of the circa 135 articles on specialized software for OR planning $[3,4]$, the majority propose predominantly mechanistic algorithms. To date there is little original data on the user experiences [5] and the social implications of steering medical processes (like OR planning) with true business process control systems like SAP, Oracle or Sage.

Therefore, the end-user problems resulting from the current push for integration of operational IT solutions into enterprise wide accounting systems were the focus of this study. The objective was to chart the perceived changes to operation planning brought on by expanding the scope of major ERP system to real-time planning. We focused on supplier-independent phenomena and the background for transformation. The hypothesis was that the ERP module raised the planners' perceived productivity and process control while respecting their previous autonomy.

\section{Material and Methods}

We conducted an independent field study [6] of the IT-based planning and steering processes for all surgical operations at two large university teaching hospitals (institution 1: 7600 staff, 1500 beds, among the largest organ transplantation centers in Europe as well as being a highly productive research campus; institution 2: 1200 staff/575 beds). Both run current versions of the SAP R3 Business Process Control System software (SAP, Waldorf, Germany). "R3" designates a family of real-time resource planning and billing software products, which incorporate all key business functions of enterprises; its various versions count among the market leading ERP systems in multinational companies. In the hospitals examined, the product had replaced a legacy scheduling network system (MCC Doit, Meierhofer AG, Munich, Germany), without either real-time or process steering features, but with radiology and laboratory links, between 0.5 and 3 years prior to the study. The ERP software was introduced to all 16 departments according to industry standards via instruction classes, power user nomination and feedback, prompting moderate system modifications.

The SAP Theatre Planning module function workflow is shown in $>$ Figure 1. Briefly, physicians and other staff fill in a request form ( $\triangleright$ Figure $2 \mathrm{a}$ ), which is then assigned a timeslot, room, and staff by the surgical department's executive theatre planner, resulting in a planning view ( $\triangleright$ Figure $2 \mathrm{a}$ ).

Quantitative data was obtained via an anonymous in-depth survey of the surgical department's senior planning executives ( $\mathrm{n}=56$ surgeons, henceforth called "Surgical planners") and senior clerical and nursing staff ( $\mathrm{n}=21$ e.g. in surgical outpatients departments, henceforth called "Clerical planners").

Inclusion criteria: Senior surgeons and senior clerical or nursing staff with current executive ITplanning rights, i.e. right to allocate time-slots and staff. Exclusion criteria: Simple user without executive planning rights; expired planning rights. 
The questionnaire design was based on the qualitative results, STROBE criteria [7] and ISO 9241-10 usability tools. It was pre-tested with non-eligible planners [8] (original questionnaire and spread sheets in Supplemental Digital Content (SDC) File 5, 6 and 7). 73 items covering usability, organizational mishaps, planning procedures etc. were explored with 80 questions. These were categorical, ordinal (based on verbally anchored uni-polar and bi-polar 5-point Likert scales [abbreviated ULS 0 to 5, BLS -2 to +2]), metric (M) and free text questions (FT) and featured neutral options. Completion time was ca. 70 minutes.

The anonymous questionnaires plus separate registration postcard for the management of two reminders were mailed conventionally. Source data was closed 22-04-15. After matrix-transfer it was computed with cross-table, mean-value and correlation statistics (Chi Square, McNemar, Mann Whitney and Fisher tests, SPSS Version 21.0) and coherent items were grouped within clinically relevant contexts. Relevant missing data are reported in brackets.

Qualitative data included 22 interviews (duration 0.5-3hrs, transcribed) with planning stakeholders (e.g. surgical department planners, head scrub nurses, Central Theatre Coordinator (CTC), IT specialists, line surgeons) and document analyses of various theatre suite and software charters.

\section{Results: Survey}

\subsection{Response rates}

Three institutions running equivalent versions of SAP were approached; two were included. The management of the third declined the opportunity to have their clinicians participate. Overall response from senior executives was 59/77 (77\%), consisting of 43/53 surgical and 16/21 clerical planners. Thus for all units $(n=16)$ included in the survey, the ERP was judged from two sides.

\subsection{User epidemiology}

Planners bore responsibility, on average, for $3.5 \pm 1.2$ ORs staffed with $12 \pm 3$ persons, belonging to up to 6 organizational parties (e.g. anesthesiology, perfusion technologists, scrub nurses).

Most respondents had used the current system for $1-3$ years (39\% statistical mode; <1 year 36\%, $>3$ years $25 \%$, missing: $8 \%$ ). 22 surgical planners (52\%) and 13 clerical planners (79\%) had personal executive experience with the previous systems. Both stated that the planning work-flow had changed considerably $(3.87 \pm 0.98$ on ULS $0-5)$.

Weekly time-expenditure for planning was between $2.5-<5$ hours (median, CAT, statistical mode: 5-<10hrs, 32\%), of which ERP system-use was said to comprise $62 \pm 34 \%(\mathrm{M})$.

\subsection{Description of planning workload and workflow}

Concerning the overall planning effort, $46 \%(n=22)$ said the new IT system increased the planning work. $8 \%(\mathrm{n}=4)$ said that it reduced it $(\mathrm{p}=0.02$; Chi Square test). $27 \%(\mathrm{n}=13)$ saw it as unchanged ("don't know": $10 \% / \mathrm{n}=5$, missing $8 \% / \mathrm{n}=4$ ).

Out of the planners, $73 \%$ reported compiling the Operating List directly in IT (SAP), while 23\% used analogue media such as paper, whiteboard or similar.

Interviews and document analyses disclosed the workflow of planning with the system ( $\triangleright$ Figure $1)$.

\subsection{Frustrations}

\section{Operation - requests}

Planners said that $28 \pm 30 \%$ of all electronic requests reaching them had significant mistakes that increased their workload (through re-checks) before assignment. The most frequent mistakes nominated by planners included incomplete requests ( $83 \%$ of all requests), contradictory information (e.g. diagnosis-procedure or duration disparities; 57\%), and "invisible requests", which never appear- 
ed on screen due to inaccurate program usage (36\%). Physician-filed requests had more mistakes than those from clerical staff (39\% vs. 21\%).

\section{Screen Organization - Relevance and Redundancy}

Concerning the electronic "Operation Request" form (which constitutes the start of a booking process) and the program's central "Planning View" (which is the main output), surgical planners said that $36 \pm 26 \%$ of the screen surface ( $\nabla$ Figure $2 \mathrm{a}$, $\triangleright$ Figure $2 \mathrm{~b}$ ) appeared irrelevant for all OR stakeholders, as it contained billing and programming specifics as well as void fields. On the other hand, the most relevant information (e.g. risk factors such as colonization with multidrug resistant germs) were not immediately discernible for $56 \%$ of planners. $70 \%$ declined a need for further mandatory fields in the request screen and said that the information content was sufficient for plausibility controls (60\%, missing: $15 \%)$.

On-screen information from the ERP system was now ranked as the favorite medium by which surgeons could inform themselves of the day's List (98\% of maximum obtainable rank points, $57 \%$ for the legacy system), replacing printouts (65\% legacy, $52 \%$ SAP).

As an overall judgment on usability, $66 \%$ of respondents reported that the SAP system was nonintuitive (CAT, missing 13\%). Only 19\% deemed it "suitable for the high risk environment" of ORs.

\subsection{Process Steering Details}

To co-ordinate standard operations, planners mostly communicated orally with ward, anesthesiology department, and scrub nurses, (77, 86 and $85 \%$ respectively, missing: $27 \%$ ). This was followed by the ERP system $(65,63$ and $68 \%$ respectively). Of the respondents, $35 \%$ communicated exclusively orally, $41 \%$ used both communication modes for co-ordination.

Co-ordination of multidisciplinary operative treatment (i.e. different surgical departments operate on the same patient during one general anesthesia): the perceived quality of co-ordination shifted from "good" (statistical mode 54\% for the legacy IT-system) to "poor" (mode $46 \%$ for the current ERP system, details SDC 3).

Management of short-term changes to the on-going program: planners estimated that 30 $\pm 19 \%$ of any schedules were dynamically altered. This included e.g. patient position in the queue, pre-planned staff or cancellations. While $86 \%$ perceived this percentage as unchanged compared to the past, currently $83 \%$ entered changes directly into the IT system (missing: 13\%). Nevertheless, the route for staff information about changes remained largely oral (proportion of oral vs. IT-mediated notifications $=3.7: 1$; formerly $4.3: 1$, difference: $n . s$. ); $31 \%$ said that the effort involved in notifications had dropped, $60 \%$ found it to be about the same (missing: $12 \%$ ).

Error Reduction: of the eligible respondents, 91\% (missing: 10\%) said that frequency and spectrum (Table 1) of organizational mishaps had remained unaltered by the system upgrade.

As to the most-cited cause, department staff now viewed "the planner" rather than "medical emergency" (legacy system; $\mathrm{p}=0.18$, details in SDC 4 ) as the most likely cause of organizational mishaps.

\section{6 (Potential) efficiency advantages}

\section{System Integration}

Out of all surgical planners, $73 \%$ used the planning system's integration with the electronic patient record (EPR) for $47 \pm 40 \%$ of cases.

\section{Change of information exchange (missing: 16\%)}

Out of all planners, 33\% said the new system "made information exchange easier overall"; 23\% found it "more difficult" while the rest reported a stable valence.

\section{Real-time features}

Among the surgical planners 52\% said they used real-time features. However, $71 \%$ said that on the screens these were neither readily discernible (missing: $17 \%)$ nor organized logically (69\%; missing: 
$15 \%)$. Respondents thought that the real-time information as it was presented had few consequences for decision making $(1.7 \pm 1.6$ on ULS $0-5)$.

\subsection{Qualitative results - concluding responses to free text questions}

Respondents named the following three factors as the most conspicuous weaknesses of the ERP system: 1 . Complicated, confusing screen organization $(n=21) ; 2$. Nested workflows with excessive drill downs, and frequent blockades due to intra-screen or screen-to-screen input dependencies $(n=15)$; 3 . Non-intuitive $(n=11)$. Four respondents concluded that the current system was more complicated than the legacy system without adding value.

The three most helpful ERP system advantages were said to be: 1 . Up-to-date information about on-going processes $(n=10) ; 2$. Information available everywhere $(n=9) ; 3$. Integration of lab results/ $\mathrm{X}$-ray/EPR $(\mathrm{n}=8)$.

Planners specified the general features of good theatre planning software: 1 . Easy-to-use and intuitive $(n=19) ; 2$. Clearly-arranged screens without information overload $(n=17) ; 3$. Fast/time-effective $(n=8)$. One respondent suggested: "a maximum of five clicks to achieve the goal". The addition of further real-time features or integration of duty roster planning functions scored low.

The general characteristics of any good OR list independent of its medium were stated as: 1 . Feasibility and robustness against adverse events $(n=19) ; 2$. Absence of information overload but highlighting of crucial items (e.g. colonization with multidrug resistant germs), $n=12$ ); 3 . Fairness and equity $(\mathrm{n}=5)$.

Asked how much the new IT system changed social aspects of operation assignment (items: equity, traceability for participants, dependence on politics, influence and power of the planner) planners' replies (BLS -2 -no change- +2) were close to the "no change" mark (0.12 $\pm 0.6 ; 0.24 \pm 0.8$; $0.08 \pm 0.09 ; 0.34 \pm 0.9)$.

\subsection{Qualitative results - interviews}

Several interviewees expressed the view that the SAP system increased speed and quality of the accounting and billing of operations and materials, but not that of medical process control. Asked to comment on the expense of the system, interviewees denied knowledge of the exact figures. Several evoked direct costs (e.g. license fees, in-house SAP-team), indirect costs, (arising from, e.g., increased workloads) and intangible costs resulting e.g. from user frustration. Interviewees noted that clinicians (especially executives) often circumvented the old IT system. In contrast, with the new ERP-system, there were complaints that time-critical processes (e.g. trauma CT) could not be initiated if not registered there.

The width of lists containing relevant information within the programmed ERP screens exceeded the hardware monitors. Modifying the ERP-software was found to be "extremely costly". Instead, planners were given wide-screen monitors of prestigious makes.

A finding from interviews with "line surgeons" (i.e. subordinate surgeons who were more beholden to the planning) and anesthetists was that planners apparently used the ERP's complexity to render planning more "exclusive" and centered it on themselves e.g. by newly issued, lengthy "ERP planning rules" that all others had to comply with.

The group of anesthesiologists in the larger institution pointed out that ERP usability problems were such that their entire service (> 130 doctors) felt compelled to maintain in parallel a "homemade", commercially unavailable but extremely user-friendly stand-alone steering system.

\section{Discussion}

In mid-winter 2012 the modern liner "Costa Concordia" sank after hitting an underwater rock that the captain claimed "was not on the map". Only six days prior to this, electronic chart systems (ECDIS, [9]) became compulsory worldwide. While the presence on the bridge of a blonde Moldavian woman inspired the media, nautical academics drew attention to the indiscernibility of obstacles within over-detailed screens as a risk factor for (deadly) disasters [10]. 
How is this connected to extending a major ERP $(\approx$ billing) system's reach to steer processes in surgical operation suites in real-time? To briefly summarize the results of the current study, ERP screens were considered to be user unfriendly and tedious. On balance, a negative impact on OR workflow and planning work was noted. In comparison to the legacy, which was a specialized semiintegrated planning system, prospective improvements e.g. reduced frequency of mishaps, were negated by the surgical end-users.

The move to extend the usage of existing ERP software to steer processes raises multiple issues. Safety and user acceptance are selected for a closer look below.

\subsection{Safety}

One extremely worrying result of our study is that $36 \pm 26 \%$ of the main screen surface contents were deemed clinically irrelevant, whereas crucial information was poorly discernible. Accordingly, planners argued against additional mandatory information boxes on the screens. Two-thirds of users deemed the ERP system workflows to be "too complicated" with the danger of "getting lost". Indeed, this problem has previously been noted for ERP software [11], whose power for economic analysis ("queries", audits and benchmarking) comes at the price of high complexity. Surgeonplanners' "primary task load" [12] is direct patient care. This work is emotionally demanding, with intense time-pressure. Thus their capacity to operate any complex planning system is limited. Multiple features and views may distract from maintaining what mariners aptly call "a proper lookout" [15].

Organizational mishaps in ORs can have strong repercussions both for patient safety and overall productivity [13]. The ERP planning module failed to perceivably alter their frequency or spectrum. Concerning the management of short-term changes, a material aspect of surgical scheduling [14] in real-time, potential efficacy advantages were not realized: e.g. for stakeholder notification, where changes in planning were necessary, one interviewee stated: "You still have to call everybody". This was reflected by the metric that the oral route still prevailed 4:1 over the ERP system.

Surprisingly, most planners reject the idea that the ERP's “real-time properties" have a positive impact on planning and safety. One possible explanation for this is that, while technically "real-time" means that any input is instantly processed, surgeons would expect that everything that happens is displayed immediately. This was not the case. The presumed reason is an input deficit: planning and running an OR-List involves a constant stream of information to the planner. It is apparently straightforward, but every so often "encoded", that is to say, knowledge (often tacit, e.g. regarding the weaknesses of individual team members) or even instinct (e.g. about the expected course in a problematic case) modify its perception. Moreover "extraneous factors" e.g. micro-political jockeying for the most prestigious operations (Europe) or convenient block-time slots (US) dynamically shape the booking process [15], to such an extent that one interviewee described it as "the other half of operation planning". Real-time updating of such a wealth of data is at the present time not possible in any existing ERP system. Therefore input capability rather than processing capacity constitutes the "bottleneck" for computerized real-time OR planning. The same lesson was learned on US aircraft carriers: Traffic on deck was traditionally controlled [16] on analogue planning tables ("Ouija boards"). IT-touch pads tried in replacement [17] surprisingly failed to decrease accidents. Likely cause - as in the OR setting: limited input capacity at the human-IT interface i.e. for data sensed and interpreted by flight deck handlers [18].

\subsection{User acceptance and its socio-economic modeling}

The study respondents had sufficient ERP system experience to exclude initial rejection bias [19]. Beyond this, acceptance depends on a system's benefit for individual users [20] rather than on attributed personality traits. "Benefit" encompasses the functional gain for a given task as well as social advantages, like increase or preservation of personal autonomy [21].

Regarding planning software functionality, respondents unanimously cited clearly structured screens and intuitive, speedy user prompts as the most important features and bemoaned their absence in the examined ERP extension. It is very telling that the anesthetists backed up the ERP sys- 
tem with a "home-made" software as a user-friendly stopgap. Evidently the absence of a shared platform for all stakeholders in the same process is unproductive and hazardous.

ERPs are considered as "invasive [22]". Therefore they elicit powerful social responses, which can either increase or decrease acceptance: Due to traceable user prompts, planners felt that more personal blame for organizational mishaps was placed on them.

Another (qualitative) finding was that the more complicated ERP system apparently consolidated the planner's position, as only they knew how to control it. This is linked to the classical paradox [23] that occasional IT malfunctions may substantiate specialist's positions by demonstrating the organization's own vulnerability.

Differentiated user experiences are considered as one main driving force [24, 25] of digital transformation. However, when a layperson's glance at the ERP surface readily suggests that these are absent, but systems are changed nevertheless it becomes clear that it is also political issues, like power distribution within hospitals [26], that determine user acceptance [27]: several interviewees expressed the view that the ERP decreased their maneuvering margins against the management e.g. by economic benchmarking of individual surgeons.

A similar line of thinking underlies the observation that the problem of large tables, which exceeded the screen, was solved by hardware change rather than by software modification. Once ERPs are in place, organizations become highly dependent on them and the phenomenon of "predatory pricing" [28] becomes relevant for a balanced appraisal of user acceptance. Initially accepted because the choice of a market-leading product shields managements from criticism in case of malfunction $[29,30]$, high cost may later hinder necessary software adoptions for frontline users.

Finally, cultural differences [31] may have contributed to the evident acceptance problem in our study: ERP complexity encapsulates the essence of hospital accountant's (and system developer's) expertise while clinical users [32] depend on directness and simplicity.

\subsection{Discussion of study methodology and limitations}

The refusal of one hospital to participate illustrates the fact that studying ERP impact holds challenges of an "anthropological" nature: When costly IT is introduced by the management, despite obvious shortcomings, collecting accounts from clinical executives becomes delicate. Their patient care performance is the principal determinant of their standing and likelihood of promotion [6]. This discourages them from getting involved in possibly controversial subjects "off the track" and favors "arrangements" e.g. by maintaining a home-made parallel system. This is a typical sequence of events in failing transformation efforts [33].

The present approach relies on expert self-reports. Their weaknesses include e.g. recall error [34]. Ideally, objective data e.g. from comparison of planned versus actual operations, return of investment calculations etc. should complement them. However, before-and-after recordings in multiple departments operating around-the-clock are unlikely to be accurate. The monitoring of a fundamental endpoint of surgery, operative complications, has already proven to be extremely unreliable [35]!

Furthermore, inclusion of more sites would have been desirable. However, a site-confined approach can capitalize on existing social relations between clinical researchers to (at times unavailable) senior surgeons and realize full inventory counts. In politically loaded subjects, especially when not sponsored by management or suppliers, these may add valuable background to large random surveys funneled through professional associations, which can suffer from inhomogeneous underlying IT infrastructures and response bias.

Research obstacles: among the important obstacles that discourage research into the importance of the IT issues in clinical practice are differences in products (according to supplier) and product versions, which impede result transferability. Focusing upon universal phenomena (like input limitation or social modeling) and studying market-leading software in centers of clinical excellence are ways to compensate for this. 


\section{Conclusion}

\subsection{What can clinicians add?}

The combination of two dominant contemporary trends, namely the progressing integration of Health IT subsystems with each other and the economization of hospital medicine makes it likely that enterprise systems are here to stay in surgery as well. However viewed abstractly, successful ERP use requires the reconciliation of economic auditing with operational benefit [36, 37]. Therefore, clinicians need to concern themselves with this task and supply quality end user data (collected according to protocols like the one presented in this study) to developers and intra-institutional stakeholders on the true ERP functionality for patient care. As in drug research, important commercial interests [38] favor lobbying. Thus data should be generated independently from suppliers or management, which means is best achieved by providing an academic incentive to investigate this (e.g. via a Masters thesis).

\subsection{What changes could add real value to ERP theatre planning?}

- all theatre planning software should offer an "S-mode" (standardized, simple, safe) [15], which contains the essential data in a commonly agreed form.

- the provision of the funding from currently important public E-health incentives [39] should be made dependent [40] on satisfying a legal requirement for safety-critical theatre planning software to incorporate such an S-mode.

- all systems should also feature mandatory E-learning/simulation modules, which ensure formalized S-mode training before user accounts can be activated.

- Rather than restricting IT-use in high-risk environments (as it occurred in the Ouija-case) an even more consistent digitalization could decrease the input deficit for the planners and help notifications in the case of short-term changes: digital ID wristbands for patients ("wearables"); and for surgeons mobile devices aided by ceiling-mounted X-boxes to allow exact localizations or status identifications ("social sensing") [41]. However, in most countries these changes require interdisciplinary judicial solutions which concern employee rights.

- Both, social factors and the previously discussed input limitations, are connected to the ERP's fundamental inability to account for "other half of OR process steering" - variables that can only be mediated by "human" interpretation with real-time adjustments. Teams are not equal and patients and procedures are not equivalent and uniformly reliable. The use of power and manipulations regarding sought after slots and procedures are not easily covered by algorithms. It would be a major improvement if system developers could design entry gates like those under consideration in air traffic control systems [42] through which these uncertain factors can be introduced to the system.

- Limiting system-override possibilities may enable trendy watertight auditing [43] but a documented consensus with front-line staff regarding safety relevant time critical actions should be actively established for system acceptance.

- Outsiders said that the ERP system complexity was used to exclude them from planning. Consequently, simpler, safer systems will empower [44] the subordinate users relative to the planners and administration. The authors believe that this is needed for ultimate system acceptance and success in the context of clinical medicine.

\section{Clinical Relevance Statement}

Unnecessary complexity of surgical operation planning modules from ERP systems may lower productivity, acceptance, and safety compared to specialized or stand-alone software. Simplification, consideration of the social processes involved in planning, and overcoming input limitations for real-time data are detailed as possibilities for real, system-independent improvement. 


\section{Multiple Choice Questions}

1. Which is a deficit of current process steering extensions of hospital wide ERP-software?

A. Improved cost control and watertight auditing

B. Good process control in real-time

C. Easy to use/user friendly

D. Interlinking with electronic health records (e.g. lab, radiology) of individual patients

Right Answer: C.

The domain of Enterprise Resource Planning software (synonym: business process control software) is an extremely refined economic analysis, which enables precise economic steering and controlling. While this carried the ERP-systems to the top throughout the corporate world, their operation demands professional expertise. As a side effect, user friendliness and ergonomic surfaces were not a main "selection factor" during their technical evolution and in the competition for market share. However when their use is to be extended beyond business and IT specialists to high-risk environments like OR-suites, this deficit in user-friendliness becomes relevant.

2. Which important factor is often neglected when designing or reviewing clinical process control software linked to enterprise systems?

A. Functionality aspects for the given tasks

B. Real-time on-screen display of the progress of the actual process (e.g. surgical operations) or of Electronic Patient Record elements (e.g. blood results for ongoing operations)

C. Precise accounting per case of used materials and work time specified for the different occupational parties involved in the actual surgery in one Operation Room.

D. The systems' implications for personal advantage and autonomy of individual users and for intraorganizational power distributions.

Right Answer: D.

Process steering software and especially enterprise systems strongly interact with social and economical processes. These include "games" among stakeholders for influence, or viewed more abstractly for "options for one's own action". These occur in the specific context of each respective hospital organization. For the process concerned in this study they make up what one participant called "the other half of operation planning" "Extraneous factors" can only be fully appreciated by a combination of quantitative and qualitative methodology, and need to be explicitly considered and communicated when designing and implementing IT systems for operational steering.

\section{Conflicts of Interest}

The authors declare that they have no conflict of interest in the research.

\section{Protection of Human Subjects}

Patients or animals were not involved. The institutions' workers' committee and legal affairs department granted permission valid for all sites (Nr. 9510, 18.7.2013).

\section{Acknowledgements}

Staff mathematician K. Rohwer-Menschig; Hannover Medical School (MHH), Germany for expert advice regarding hospital SAP, W. Lynas, MA, Copenhagen and J. K. Moran, PhD, Berlin for editing, Prof. S. Geyer; Medical Sociology Unit MHH Hannover, Prof. G. Grote, Organizational Psychology, ETH Zurich and Prof. Windeler, Sociology TU Berlin for valuable advice during the initial and final stages of this study.

List of Supporting Digital Content (SDC)

SDC 1-4.docx; SDC 5 Questionnaire.docx; SDC 6 spread sheet.xlsx, SDC 7 code plan.xlsx 


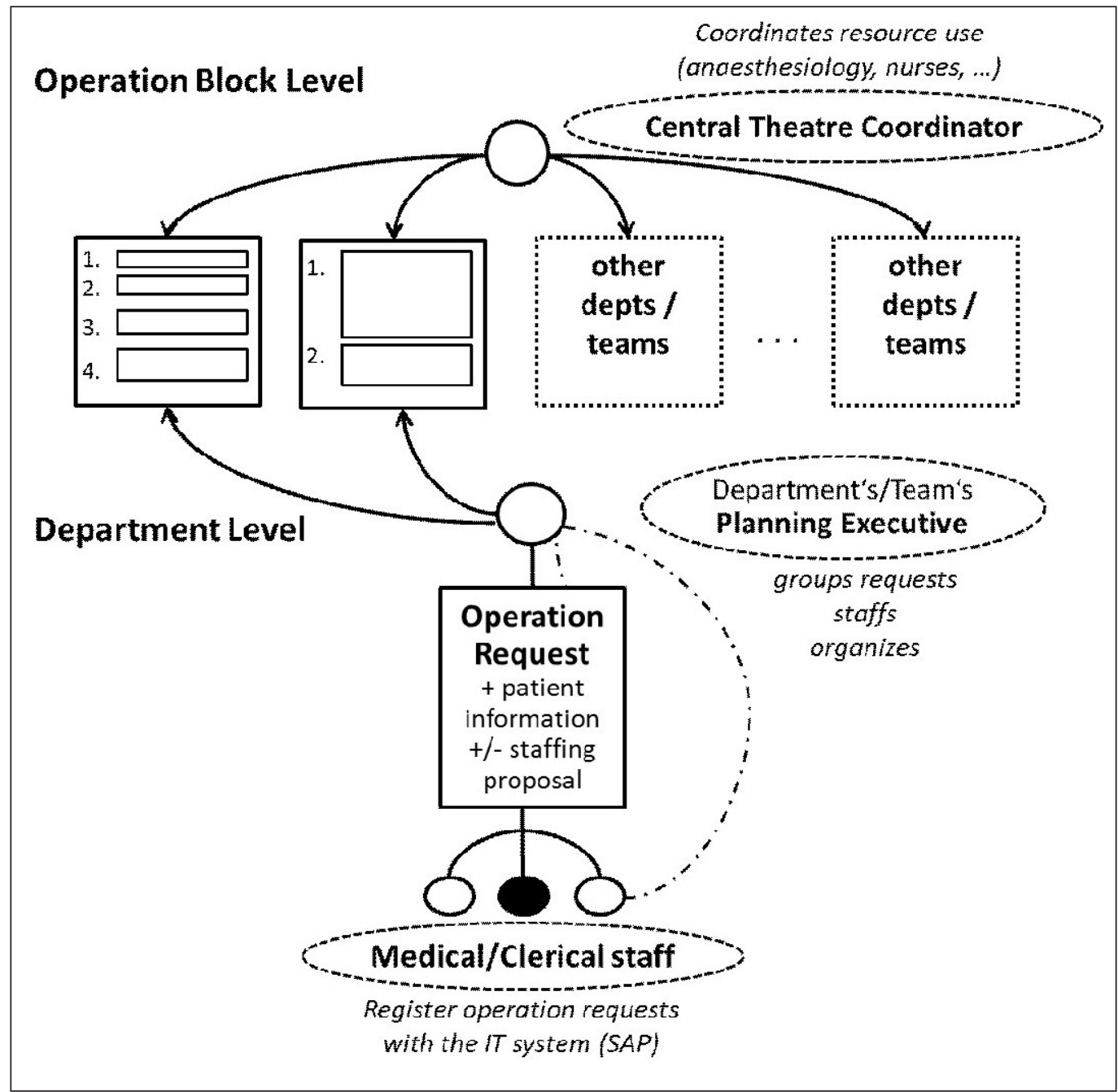

Fig. 1 Compiling Surgical Operation Lists. Actual planning workflow involving an ERP-derived IT planning tool. 


\section{Research Article}

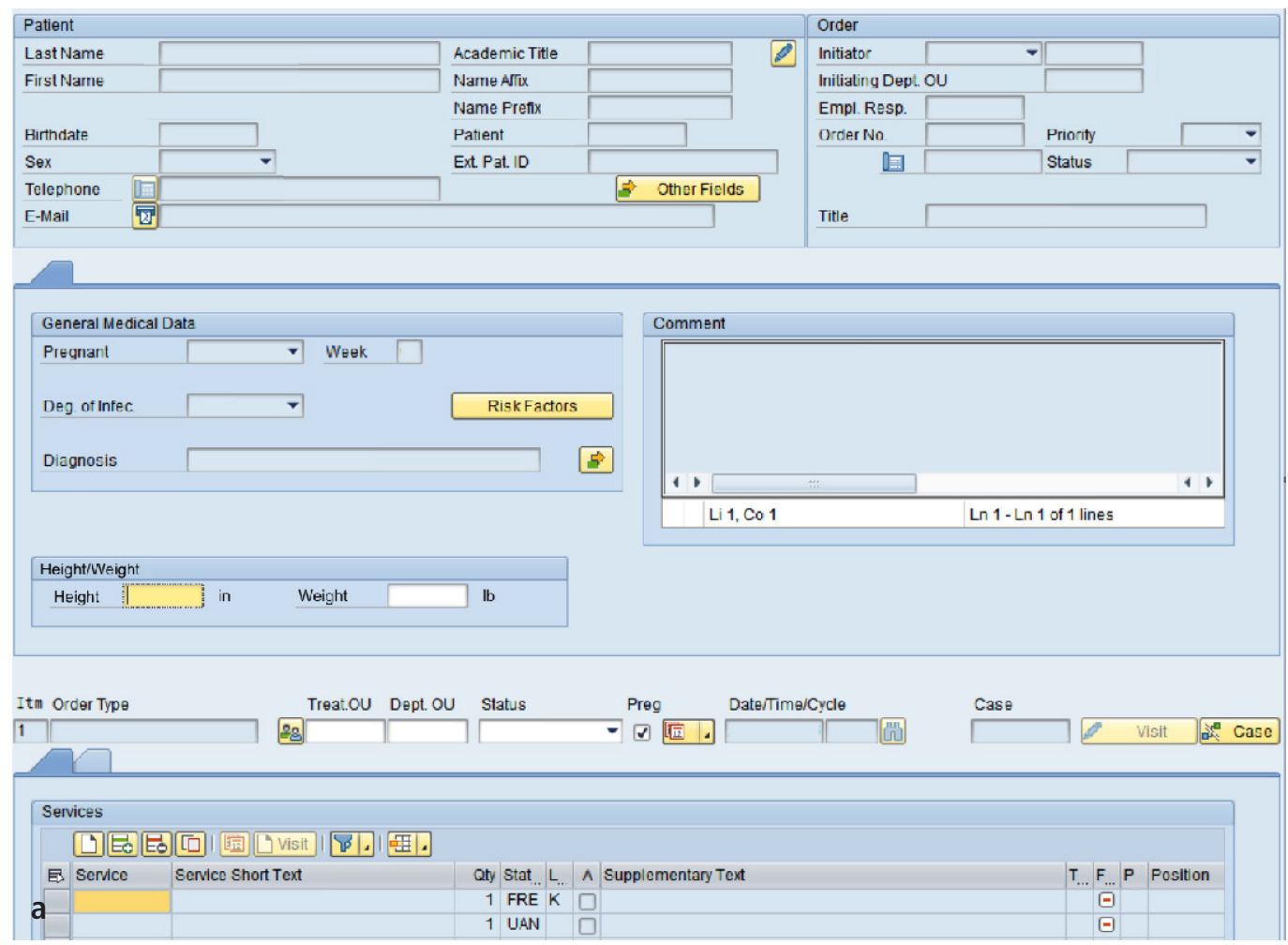

Fig. 2a Screen organization of two central views of the SAP R3 Planning Module. a) Electronic "Operation Request"

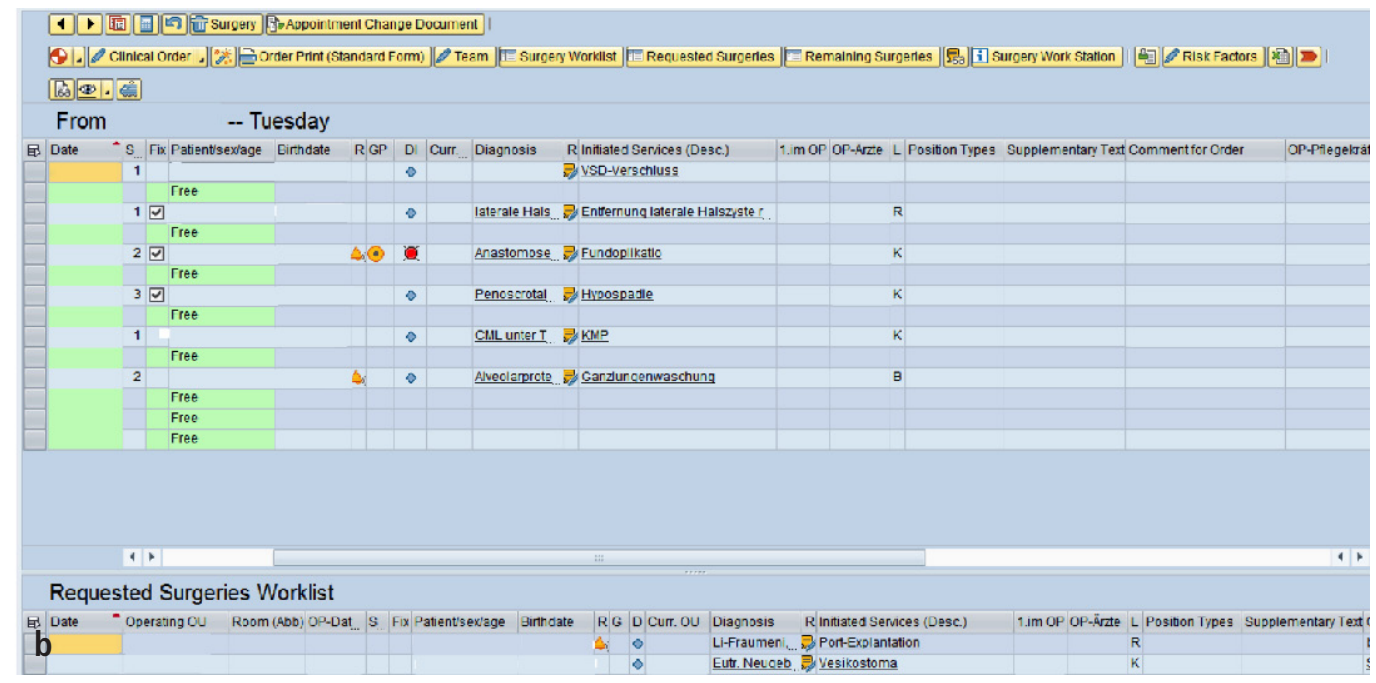

Fig. 2b Central "Planning View". Both screens contain significant proportions of non-specific information (e.g. billing, void space etc.). 
Table 1 Organizational mishaps experienced by respondents within the last three months prior to their reply.

\begin{tabular}{|l|l|l|l|l|}
\hline $\begin{array}{l}\text { Type of organizational mishap/failure (valid } \\
\mathbf{n = 3 4} \text { ) }\end{array}$ & $\begin{array}{l}\text { before SAP } \\
\mathbf{n}\end{array}$ & $\begin{array}{l}\text { since SAP } \\
\mathbf{n}\end{array}$ & $\begin{array}{l}\Delta \mathbf{n} \\
\mathbf{p} \Delta \\
\text { (Wilcoxon) }\end{array}$ \\
\hline Cancellation in premedicated patients & 28 & 28 & 0 & 1 \\
\hline Empty OR despite demand & 23 & 26 & +3 & 1 \\
\hline Cancellation with surgical team present & 19 & 19 & 0 & 1 \\
\hline Cancellation with loss of perishable blood product & 14 & 13 & -1 & 1 \\
\hline Cancellation due to lack of equipment & 14 & 16 & +2 & 0.317 \\
\hline Cancellation due to incomplete team & 7 & 9 & +2 & 1 \\
\hline None & 2 & 2 & 0 & 1 \\
\hline Other & 0 & 1 & +1 & 1 \\
\hline
\end{tabular}




\section{References}

1. Dexter F1, Willemsen-Dunlap A, Lee JD. Operating room managerial decision-making on the day of surgery with and without computer recommendations and status displays. Anesth Analg 2007; 105: 419-429.

2. Puschner P, Koza C. Calculating the maximum execution time of real-time programs. Real-Time Systems 1989; 1 : 159-176.

3. Ogulata SN, Erol R. A hierarchical multiple criteria mathematical programming approach for scheduling general surgery operations in large hospitals. J Med Syst 2003; 27: 259-270.

4. Samudra M, Demeulemeester E, Cardoen B, Vansteenkiste N, Rademakers FE. Due time driven surgery scheduling. Health Care Manag Sci 2016 Feb 9.

5. Sakowska MM, Thomas MV, Connor S, Roberts R. Hospital-wide implementation of an electronic-workflow solution aiming to make surgical practice improvement easy. ANZ J Surg 2016 Oct 21. doi: 10.1111/ans.13805.

6. Babbie, E. The Practice of Social Research. Wadsworth: Cengage Learning, 2012.

7. von Elm E, Altman DG, Egger M, , Pocock SJ, Gøtzsche PC, Vandenbroucke JP. STROBE Initiative. The Strengthening the Reporting of Observational Studies in Epidemiology (STROBE) statement: guidelines for reporting observational studies. Lancet 2007; 370: 1453-1457.

8. Vogt DS, King DW, King L. „Focus groups in psychological assessment: enhancing content validity by consulting members of the target population." Psychological assessment 2004; 16: 231.

9. Weintrit, Adam. The electronic chart display and information system (ECDIS): an operational handbook. Boca Raton: CRC Press; 2009.

10.Pleskacz K, Janusz U. „Understanding of navigational information systems.“ Annual of Navigation 2012; 19(1): 121-132.

11.Bansak N, Negi T. A metric for ERP complexity. In: Business information systems. Heidelberg: Springer, 2008. p. 369-379.

12.Eggemeier, FT., Wilson GF., Kramer AF. Workload assessment in multi-task environments. Multiple-task performance 1991, 207-216.

13. Ehrenfeld JM, Dexter F, Rothman BS, Johnson AM, Epstein RH. Case cancellation rates measured by surgical service differ whether based on the number of cases or the number of minutes cancelled. Anesth Analg 2013; 117: 711-716.

14.Epstein RH, Dexter F. Management implications for the Perioperative Surgical Home related to inpatient case cancellations and add-on case scheduling on the day of surgery. Anesthesia \& Analgesia 2015; 121: 206-218.

15. Engelmann C, Grote G, Geyer S, Ametowobla D. Operating lists are created by rational algorithms and use of power. What can a social scientific view offer surgeons? Essay. Langenbecks Arch Surg. 2016 Oct 14. PMID: 27743031

16. Roberts KH. „Some characteristics of one type of high reliability organization." Organization Science $1990 ; 1.2: 160-176$.

17. Johnston JS., Swenson ED. „Feasibility Study of Global-Positioning-System-Based Aircraft-Carrier FlightDeck Persistent Monitoring System." Journal of Aircraft 2010; 47.5: 1624-1635.

18. Henry T, CDR USS Eisenhower CVN-69, E-mail, March 02, 2015.

19.Szabla DB. „A multidimensional view of resistance to organizational change: Exploring cognitive, emotional, and intentional responses to planned change across perceived change leadership strategies." Human Resource Development Quarterly 2007; 525-558.

20.Wagner EL, Piccoli G. „Moving beyond user participation to achieve successful IS design.“ Communications of the ACM 2007; 50 (12): 51-55.

21. Jones EE, Davis KE. From acts to dispositions: The attribution process in person perception. In L. Berkowitz L, editor. Advances in experimental social psychology (Vol. 2). New York: Academic Press, 219-266, 1965.

22. Wears RL. Health information technology and victory. Ann Emerg Med 2015; 65: 143-145.

23. Crozier M, Friedberg E. Actors and systems: The politics of collective action. Chicago: University of Chicago Press; 1980.

24. Sellen A, Rogers Y, Harper R, Rodden T. Reflecting human values in the digital age. Communications of the ACM 2009; 52(3): 58-66.

25. Institute for business value. Thinking out of the toolbox: How digital technologies are powering the operations revolution http://www.oxfordeconomics.com/my-oxford/projects/322883, accessed 10-2-2017.

26. Lynne MM. Power, politics and MIS implementation. Communications of the ACM. ACM New York, NA 1983; $26: 430-444$. 
27. Kayas OG, McLean R, Hines T, Wright GH. The panoptic gaze: Analysing the interaction between enterprise resource planning technology and organisational culture. InternationalJ ournal of Information Management 2008; 28(6): 446-452.

28. Kittlaus HB, Clough PN. Software product management and pricing: Key success factors for software organizations. Luxemburg: Springer Science \& Business Media, 2008.

29. Ortmann G, Windeler A, Becker A, Schulz, H J. [Computers and Power in Organizations: Micropolitical Analyses]. Opladen: Westdeutscher Verlag. German. 1990.

30. Harrison MI, Koppel R, Bar-Lev S. Unintended consequences of information technologies in health care an interactive sociotechnical analysis. J Am Med Inform Assoc 2007; 14: 542-549.

31.Zakour, AB. Cultural differences and information technology acceptance. In: Proceedings of the 7th annual conference of the Southern association for information systems. 2004. p. 156-161.

32.Dietrich, R, Childress TM. Group interaction in high risk environments. Farnham/Surrey: Gower Publishing; 2004.

33. Kotter JP. Leading Change: Why Transformation Efforts Fail. Harvard Buisiness Review 1995: 95204.

34. Reynolds CR, Ramsay MC. Bias in psychological assessment: An empirical review and recommendations. Chapter 4. In: Handbook of Psychology, Hoboken: Wiley, 2003. p. 82-108.

35.Dindo D1, Hahnloser D, Clavien PA. Quality assessment in surgery: riding a lame horse. Ann Surg 2010; 251: 766-771.

36. Kmieciak R, Michna A, Meczynska A. „Innovativeness, empowerment and IT capability: evidence from SMEs.“ Industrial Management \& Data Systems 2012; 112(5): 707-728.

37.Langley A,, Denis JL. „Beyond evidence: the micropolitics of improvement.“ BMJ Qual Saf 2011; 20: i43-i46.

38. Koppel R., Lehmann CU. Implications of an emerging EHR monoculture for hospitals and healthcare systems. J Am Med Inform Assoc 2015; 22: 465-471.

39.EHR Incentive Programs. Data and Program reports. 2016 [Cited 2016, April 6]; available from: https://www.cms.gov/Regulations-and-Guidance/Legislation/EHRIncentivePrograms/DataAndReports. html.

40. Koppel R. Demanding Utility From Health Information Technology. Ann Intern Med 2013; 158: 845-846.

41.Korn O, Funk M, Schmidt A. Assistive Systems for the Workplace: Towards Context-Aware Assistance. Assistive Technologies for Physical and Cognitive Disabilities 2015; 121-133.

42.Devasia, S., Iamratanakul, D., Chatterji, G, Meyer, G. Decoupled conflict-resolution procedures for decentralized air traffic control. Intelligent Transportation Systems, IEEE Transactions 2011; 12(2): 422-437.

43. Power, M. „Research evaluation in the audit society.“ Wissenschaft unter Beobachtung. VS Verlag für Sozialwissenschaften/Germany, 2008. p.15-24.

44.Davenport TH. Process innovation: reengineering work through information technology. Boston: Harvard Business Press; 2013. 